\title{
Em busca de reconhecimento nas periferias urbanas. U ma breve comparação entre $b$-boys do Rio de Janeiro e rappers de Lisboa ${ }^{1}$
}

Otávio Raposo ${ }^{2}$

\section{Resumo}

Neste artigo comparo o modo criativo como dois grupos de jovens - $b$-boys da Maré, favela do Rio de Janeiro, e rappers da Arrentela, subúrbio de Lisboa - apropriam-se dos respectivos estilos culturais para fazerem-se visíveis e questionarem as noções dominantes sobre o seu lugar social, contribuindo na construção de novos significados sobre a sua identidade enquanto jovens pobres e negros. Ambos os grupos utilizam a componente performativa como uma forma de ascender a uma existência valorizada, ao mesmo tempo em que constroem parâmetros mais abrangentes de inserção nos territórios da cidade. No entanto, há diferenças no modo como eles apropriam-se do hip-hop e desenvolvem estratégias para romper com a segregação.

Palavras-chave: juventude, hip-hop, periferia, Maré, Arrentela

${ }^{1}$ Este artigo foi publicado originalmente no livro Hip-hop, Cultura y Participación. La visibilidad da la juventud de las periferias urbanas, com o título de "Redes Periféricas Transatlánticas II: Brasil y Portugal en foco" (RAPOSO, 2015).

2 Doutor em Antropologia pelo Instituto Universitário de Lisboa (ISCTE-IUL) e pós-doutorando em Antropologia pelo Centro de Investigação e Estudos de Sociologia (CIES-IUL), em Portugal. Agradeço à Fundação para a Ciência e a Tecnologia (FCT) pelo financiamento da pesquisa que dá lugar ao presente artigo. E-mail: otavio_raposo@ iscte.pt 


\section{In search of recognition in urban outskirts. A brief comparison between b-boysfrom Rio de Janeiro and rappers from Lisbon}

\section{Abstract}

In this article, I compare the creative way in which two groups of young people - b-boys from Maré, a favela (shanty town) in Rio de Janeiro, and rappers from Arrantela, a suburb of Lisbon - appropriate cultural styles to make themselves visibles and question prevailing ideas about their place in society, contributing towards new meanings for their identity as poor, young, black people. Both groups make use of performance as a way to feel their existence is valued, at the same time building more wide-reaching parameters for integration into their cities. There are differences, however, in the ways in which they appropriate hip-hop and create strategies to break down segregation.

Keyword: youth, hip-hop, outskirts, Maré, Arrentela

Desde o aparecimento dos rockers, vive-se uma explosão de culturas juvenis (mods, punks, teddy boys, etc.), agora impulsionada pelos rappers, $b$-boys, funkeiros ${ }^{3}$, surfistas, góticos, emos e outros. A era da globalização passou a conectar diferentes países, culturas e organizações, criando identidades partilhadas

\footnotetext{
${ }^{3} \mathrm{O}$ funk carioca é o estilo musical mais popular nas favelas do Rio de Janeiro, cujos inúmeros bailes atraem mais de um milhão de jovens todos os finais de semana. Os bailes black dos anos setenta são considerados os "embriões" do funk carioca, quando a influência da música negra norte-americana (designadamente o funk e o soul) começou a fazer sucesso nos subúrbios da cidade. Tais estilos não foram imunes às influências da musicalidade brasileira e, aos poucos, foram sendo traduzidos à realidade carioca pelos seus protagonistas, o que deu origem a novos ritmos. Nesse processo de hibridização, a influência do Miami Bass também se fez notar no funk carioca, cujas batidas sonoras passaram a ser acompanhadas por letras em português. Cf, VIANNA, 1997.
} 
para um público comum e transnacional. Presentemente, há jovens em todo o mundo que cantam rap ou dançam break dance, vertentes da chamada "cultura hip-hop". Eficiente meio de afirmação identitária e de conquista de visibilidade, é utilizada por jovens da periferia de Lisboa, Portugal, e do Rio de Janeiro, Brasil, para tentar contrariar o estatuto de subalternidade a que estão sujeitos. Neste artigo, comparo o modo criativo como dois grupos de jovens - $b$-boys da Maré (favela do Rio de Janeiro) e rappers da Arrentela (subúrbio de Lisboa) - apropriam-se dos respectivos estilos culturais para fazerem-se visíveis e questionarem as noções dominantes sobre o seu lugar social, contribuindo na construção de novos significados sobre a sua identidade enquanto jovens pobres e negros. Ambos os grupos utilizam a componente performativa como uma forma de ascender a uma existência valorizada, ao mesmo tempo em que constroem parâmetros mais abrangentes de inserção nos territórios da cidade. No entanto, há diferenças no modo como eles apropriam-se do hip-hop e desenvolvem estratégias para romper com a segregação. Se entre os b-boys da Maré a pobreza e o estigma de viver na favela são entendidos como os maiores empecilhos para obter reconhecimento e realizar uma mobilidade social ascendente, entre os rappers da Arrentela a barreira mais alta a ser superada é o racismo da sociedade portuguesa.

\section{Estilo de vida entre os rappers da Arrentela}

Os rappers da Arrentela fazem parte do Red Eyes Gang 5 , um coletivo informal de amigos criado em 1995 a partir do surgimento de várias bandas de rap no bairro. Apesar da existência da

\footnotetext{
${ }^{4}$ O hip-hop é um movimento cultural urbano, geralmente associado à música rap, que integra quatro vertentes: rap, djing, break dance e graffite. Os dois primeiros correspondem à música rap; o break dance afirmou-se como o estilo de dança característico do hip-hop; e o graffite é a sua vertente gráfica.

${ }^{5} \mathrm{O}$ nome Red Eyes Gang é uma referência aos efeitos do cigarro de haxixe nos olhos de quem o fuma, tornando-os vermelhos. Fumar haxixe é uma prática usual entre esses jovens.
} 
palavra gang, esse grupo não tem ligação com a criminalidade, tampouco possui algum tipo de organização interna, hierarquia ou rituais de admissão. Podemos considerar o Red Eyes Gang como uma $c r e w^{6}$, e a sua criação está associada às influências mediáticas que recebeu das culturas juvenis norte-americanas ligadas ao hip-hop. Com uma forte ligação territorial, o Red Eyes Gang é o resultado organizativo da afirmação da amizade no interior do grupo e do sentimento de pertença ao bairro da Arrentela ${ }^{7}$. Possibilita, ainda, uma maior projeção das músicas dos jovens que o integram, constituindo-se como o emblema de uma identidade localmente construída.

Com idades que variavam dos 16 aos 30 anos, mais de uma centena de jovens afirmavam integrar o Red Eyes Gang ${ }^{8}$, principalmente rapazes. ${ }^{9}$ Todos eles eram oriundos de camadas socialmente desfavorecidas, maioritariamente negros (seus pais eram imigrantes africanos), mas existia uma significativa presença de portugueses brancos no interior do grupo. Apesar de quase todos terem nascido em Portugal, a diversidade de origens nacionais entre os jovens negros que integravam a crew era notória (Cabo Verde, Angola, Guiné-Bissau) e espelhava a heterogeneidade étnica e cultural dos moradores do bairro. A convivência estabelecida pelos jovens do grupo excluía separações nas suas sociabilidades, consoante a cor da pele ou origem nacional. Podíamos encontrar, na mesma esquina, jovens de origem africana - de vários países - ao lado de portugueses brancos, todos vestidos de forma parecida, usando os mesmos adereços e mane-

\footnotetext{
${ }^{6}$ Muito comum no movimento hip-hop, as crews correspondem a grupos de jovens que se reveem em práticas comuns, neste caso o rap, e que se juntam sob o mesmo nome.

${ }^{7}$ A Arrentela é um bairro do Seixal, cidade que integra a Área Metropolitana de Lisboa. Vivem no Seixal pouco mais de 150 mil habitantes, dos quais mais de $60 \%$ vieram de outros distritos do país e cerca de 13\% são imigrantes, segundo dados dos Censos de 2011. ${ }^{8}$ A pesquisa sobre o Red Eyes Gang foi realizada entre 2005 e 2007 no âmbito do mestrado em Antropologia Urbana.

${ }^{9}$ A menor frequência feminina nos tradicionais pontos de convívio do grupo - esquina, muro, bar ou café - explica, em parte, o pequeno número de raparigas no seio da crew, cuja presença não ultrapassava $1 / 4$ do total dos integrantes.
} 
jando os mesmos códigos de conduta: gírias, posturas, estilos. A pertença étnica não estabelecia uma forte influência na construção das suas redes de amizade internas, nem era determinante na adesão ao Red Eyes Gang. Contudo, havia uma forte hostilidade contra eles por parte da maioria dos moradores brancos do bairro, como refere Chullage, rapper e um dos líderes informais da crew:

Há bué ${ }^{10}$ mistura, essa cena da nacionalidade tá-se tudo a cagar, mesmo os portugueses, alguns portugueses tão-se a cagar, tás a ver. Muitas vezes nem dás conta que o gajo ${ }^{11}$ que está a falar crioulo ${ }^{12}$ é angolano e isso e aquilo. Este é um dos aspectos mais positivos, não há divisão neste aspecto [...] Há muitos angolanos que sabem falar crioulo, muitos mesmo, e há bué da portugueses que sabem falar crioulo. Mas atenção! Os portugueses são bué racistas em relação a nós, eu estou a falar dos mais novos. Entre aqueles que "param", mas não são muitos os portugueses que "param" conosco, entre aqueles que "param" não há divisão neste aspecto, entre os que não "param" há uma forte divisão e desconfiança. (Informação verbal) ${ }^{13}$

Embora a prática do rap fosse a atividade estruturante do Red Eyes Gang, não era necessário ser rapper para fazer parte do grupo. Era o conjunto de vivências partilhadas nas ruas do bairro que determinava a pertença a essa crew, tal como a adesão a um estilo de vida rap. Esse era um dos principais componentes identitários do Red Eyes Gang, fornecendo conteúdo para a formulação de uma identificação coletiva. 0 estilo rap abastecia os

\footnotetext{
${ }^{10}$ De origem angolana, a palavra bué significa "muito" e foi incorporada no linguajar dos jovens de Lisboa.

${ }^{11}$ Gajo tem um significado semelhante ao de "cara", podendo ter um tom jocoso ou pejorativo.

${ }^{12} \mathrm{O}$ crioulo é a língua falada nos arquipélagos de Cabo Verde e na Guiné-Bissau, cuja fonética tem várias semelhanças com o português e múltiplas variações internas.

${ }^{13}$ Entrevista concedida ao autor pelo rapper Chullage no dia 30 de agosto, 2005, Seixal/ Portugal.
} 
jovens com informações e material performativo que os orientava no seu quotidiano ao delinear estratégias de conduta perante os desafios enfrentados. A linguagem, as preferências musicais e estéticas, a ornamentação corporal, as opções de lazer e certos rituais (FEIXA, 1999) eram alguns dos múltiplos elementos que unificavam o estilo de vida desses jovens, criando uma "narrativa de auto-identidade" (GIDDENS, 1995). Como alerta Anthony Giddens, um estilo de vida deve ser compreendido em intrínseca relação com o quotidiano, dado serem práticas rotinizadas, que servem de orientação para as práticas e experiências nos mais diversos espaços sociais. Para este autor:

Um estilo de vida pode ser definido como um conjunto mais ou menos integrado de práticas que um indivíduo adopta, não só porque essas práticas satisfazem necessidades utilitárias, mas porque dão forma material a uma narrativa particular de auto-identidade. (GIDDENS, 1995, p.75)

Portanto, o estilo de vida é uma maneira de ser e de se comportar associada a um tipo de apropriação simbólica do quotidiano por um determinado segmento social (VELHO, 1987).

A influência do estilo rap podia ser facilmente visualizada nos variados penteados de inspiração africana (tranças, rastas, etc.) e nas roupas esportivas adotadas pelos jovens: camisas com símbolos associados ao hip-hop, jeans e outras calças largas, casacos avantajados com capuz, camisas de times de futebol, tênis de marca, bonés e lenços na cabeça e acessórios diversos (brincos, cordões e pulseiras douradas ou de semente africana). 0 uso do crioulo como língua corrente entre eles, tal como certos gestos e comportamentos, não só expressava sociabilidades alternativas inspiradas no estilo rap, como promoviam a pertença e a inserção a uma comunidade afetiva, neste caso, ao Red Eyes Gang. 
Imagem 1: Rapper da Arrentela

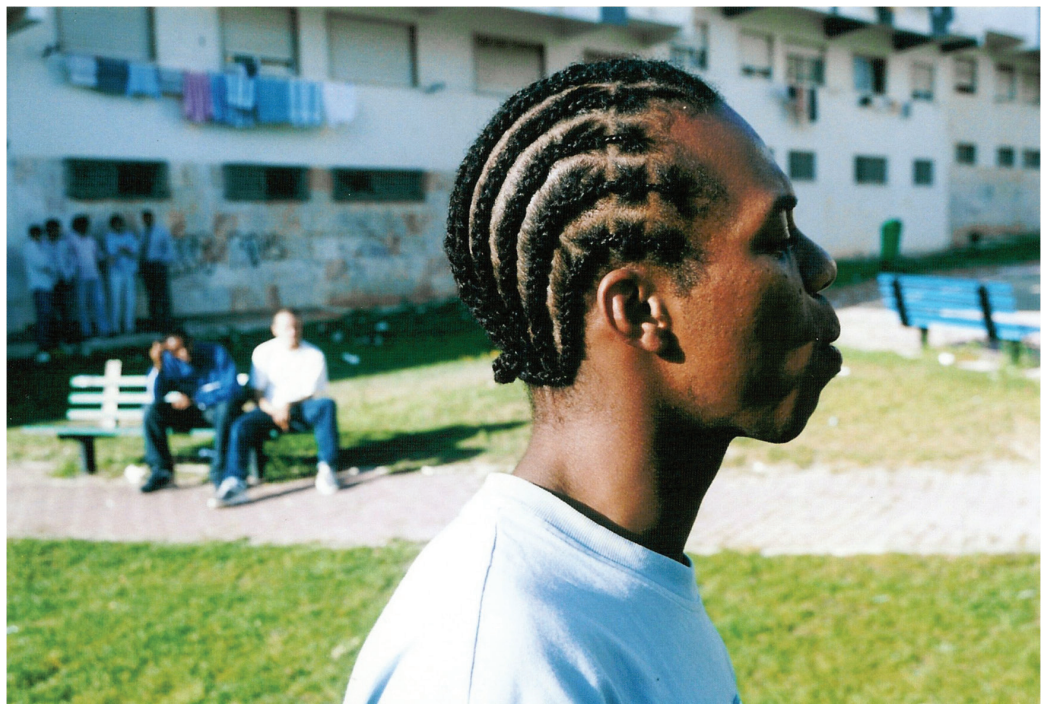

(Fotografia de Otávio Raposo, Julho 2004)

A adesão ao estilo rap e à crew legitimava a afirmação de um jeito próprio de ser jovem, que fazia das ruas da Arrentela o centro das suas sociabilidades. Por isso, cantar rap no espaço público, rir e conversar alto à noite, passear de carro/moto em alta velocidade ou fumar cigarros de haxixe eram rituais de desobediência às regras dos adultos e fomentavam uma subjetividade particular. Eram manifestações simbólicas pelo usufruto do direito à juventude que tentavam contrariar um estatuto subalterno que lhes dificultava a prática do lazer. Através da música rap, esses jovens exerciam o "poder da palavra" e afirmavam-se como protagonistas para o seu grupo de pares e para o conjunto da sociedade, rompendo barreiras num meio autista e pouco propenso a escutá-los. A palavra preenche e fornece esperança a uma vida que já não faz sentido, recuperando referências culturais e étnicas importantes, ao mesmo tempo em que denunciam uma vida de opressão. É o que explica Chullage. 
Tu numa sala de aula não tens direito a te exprimir; no tribunal não tens direito a te exprimir; tu na entrevista de trabalho não tens direito a exprimir a tua oralidade, os teus gestos. Já vão dizer que isto não é de acordo com a normativa de comunicação europeia. Tu no telejornal ou na televisão não tens espaço para te exprimir, não tinhas nenhum espaço. E o rap criou um espaço que trazia isso tudo. 0 rap informava o people no bairro, educava o people, e ao mesmo tempo entretinha o people. Juntou ali várias coisas numa só, foi uma bomba. Naquele tempo tu vias aquilo: Ooh man! Eu posso falar para os meus niggaz ${ }^{14}$ através do rap, fazê-los dançar, fazê-los ouvir, fazê-los aprender e fazê-los mobilizarem-se por determinadas causas. (Informação verbal) ${ }^{15}$

O estilo rap dos jovens Red Eyes Gang não pode ser resumido a um mero recurso estético, pois influenciava os comportamentos e as atitudes dos seus membros. Produzia conteúdos simbólicos e ideológicos utilizados pelos jovens da crew como forma de inverter o seu baixo estatuto, desconstruindo através do rap os discursos que os associavam à violência, à passividade e à pobreza. Portanto, o estilo rap era a principal linguagem para interpretar a realidade à sua volta, insurgindo-se contra uma sociedade que os desvalorizava.

\section{Coreografias da Amizade. O s jovens do break dance da Maré}

A prática do break dance teve início na Maré em 2001, quando uma Organização Não Governamental local passou a administrar oficinas de hip-hop no bairro. 0 sucesso dessas oficinas fez emergir um pequeno grupo de b-boys e b-girls (dançarinos de

\footnotetext{
${ }^{14}$ Expressão utilizada pelos jovens negros de Lisboa para se autodesignarem, cuja origem vem do rap norte-americano: um famoso grupo de rap da Califórnia chama-se N.W.A. (Niggaz With Atittude).

${ }^{15}$ Entrevista realizada no dia 12 de maio de 2006, Seixal/Portugal, no âmbito do documentário "Nu Bai. 0 rap negro de Lisboa" (RAPOSO, 2006), 65 minutos. Para ver o filme: https://vimeo.com/15137491
} 
break dance) na Nova Holanda, uma das favelas que compõem a Maré, Rio de Janeiro.

Foi a partir de 2007 que o número de dançarinos no bairro cresceu exponencialmente, período em que alguns jovens manifestaram a vontade de ter um espaço próprio onde pudessem treinar mais vezes do que era permitido. Essa vontade só pôde ser concretizada quando conheceram os dançarinos do morro do Timbau, favela da Maré dominada por uma quadrilha do tráfico de drogas rival à da Nova Holanda. Nessa altura, eram raros aqueles que já tinham ido alguma vez para lá. 0 temor de serem confundidos com membros de uma quadrilha inimiga dificultava a mobilidade pela Maré e asfixiava as suas redes de amizade e de vizinhança.

A Maré é um conjunto de dezesseis favelas onde vivem cerca de 140 mil pessoas (REDES, 2014). É considerado o maior conjunto de favelas do Rio de Janeiro, no qual várias quadrilhas armadas disputam a hegemonia territorial ${ }^{16}$. Os seus moradores são obrigados a conviver com os constantes confrontos armados entre traficantes, agravados pela ação truculenta da polícia, o que dificulta a livre circulação pelo bairro particularmente aos jovens ${ }^{17}$. As rivalidades entre as diferentes quadrilhas do tráfico produzem divisões territoriais que constrangem as sociabilidades da sua população, refém de uma autoridade violenta e ilegítima.

Foi a vontade de dançar mais vezes e de aprofundar o conhecimento sobre o estilo que levou os b-boys da Nova Holanda a perderem o medo de ir para o Timbau. Aos poucos, passaram a frequentar localidades do bairro até então desconhecidas e a serem identificados pelos traficantes locais como "pessoal do

${ }^{16}$ Para maiores informações sobre a história da Maré, consultar: RAPOSO, 2012; SILVA e BARBOSA, 2005.

${ }^{17}$ Em 2009, ano em que iniciei a pesquisa na Maré, havia três quadrilhas a dominar as favelas, além da milícia, grupo paramilitar composto por policiais, bombeiros e militares, que exercem um controle violento e territorial parecido com o desenvolvido pelo tráfico. 
hip-hop". Percorrer o conjunto dos territórios da Maré possibilitou uma nova compreensão do bairro onde viviam e ampliou suas redes de amizade, diminuindo os efeitos da fragmentação decorrente da violência e da segregação. A intensa relação com a dança unificou os grupos da Nova Holanda e do Timbau, celebrada com a formação de uma crew representativa de todos os b-boys e b-girls da Maré: Ativa Breakers. A sua criação também servia para identificá-los nos campeonatos e eventos de dança.

No período em que acompanhei os dançarinos da Maré, o local de treino principal já não era no morro do Timbau, mas na Tecno, uma associação cultural ainda em processo de formalização localizada no Parque União, favela vizinha à Nova Holanda. Entre vinte a trinta dançarinos encontravam-se regularmente nesse espaço, a maioria deles com idades entre 16 e 20 anos. Embora a maior parte dos b-boys do bairro fosse negra, a mistura de tons de pele era predominante, o que se revelava amplamente nas suas redes de amizade dentro e fora dos ensaios. Havia poucas b-girls no bairro, situação que se repetia em campeonatos e eventos de break dance no Rio de Janeiro: não chegavam a 1/4 dos participantes.

A Tecno era o principal ponto de encontro do grupo, e as dinâmicas dos seus treinos eram impulsionadas pelos próprios dançarinos, não havendo professores ou pessoas de fora a interferirem. Eram "sociabilidades desafogadas", termo cunhado por José Machado Pais (1994, p.115), pois eram os próprios jovens a definir o formato dos treinos (movimentos a ensaiar, músicas a ouvir, horários dos ensaios, orientação dos iniciantes) e a garantir aspectos logísticos: limpeza e iluminação do espaço, sistema de som, etc. A aprendizagem de break dance era feita pelo contato direto com os membros mais experientes do grupo mediante um processo de educação corporal transmitido através da prática (BOURDIEU, 2007). Costumavam treinar fora ou dentro da "roda", momento em que cada um deles tinha de esperar a sua vez para dançar no seu centro. Uns concentravam-se num único 
movimento, geralmente mais acrobático (os chamados power movies); outros criavam sequências de movimentos, alternando aqueles feitos em pé numa cadência funk estilizada (top rock), os executados no chão com as mãos a servir de apoio (foot work) e os freezes, quando o dançarino congela um determinado movimento numa pose difícil. As risadas, os aplausos, os assobios e outras ações conectavam todos numa teia de cumplicidade dentro de um ambiente de comunicação comum. Antes de iniciar a dança os jovens preparavam-se metodicamente. 0 cuidado com que punham o boné na cabeça e a maneira vaidosa como se vestiam chamou-me a atenção para a importância no modo como eles mobilizavam estes sinais de distinção. As "fachadas visuais" são essenciais para os jovens exprimirem a sua pertença a um determinado estilo de vida e reforçarem a sua adesão aos grupos de pares (PAIS, 2004, p.43). Fonte de identificação grupal, o vestuário possibilita uma convergência estética impulsionadora de espaços de pertença, dando suporte às suas interações. A maioria vestia camisas coloridas com símbolos e frases associados ao hip-hop (por vezes dos campeonatos em que tinham participado) ou com desenhos de ícones da música negra: James Brown e Bob Marley eram os preferidos. Os bonés de aba plana eram generalizados, e alguns também punham lenços, gorros e outros adereços, além da joelheira e cotoveleira. Os tênis constituíam o objeto mais valioso dos dançarinos - All-Star, Nike e Adidas eram os mais utilizados - , pois é com eles que devem executar movimentos complexos e exigentes de estabilidade. Alguns deles diziam dançar melhor quando vestidos dessa maneira. É o caso de Igor, um dos fundadores do Ativa Breakers, cujo papel de liderança entre os dançarinos se fazia notar:

Quando eu coloco esse tipo de roupa eu me sinto como se tivesse numa roda de breaking daquela época, então me dá aquela empolgação de dançar. Minha postura muda quando eu chego na roda: ponho a mão na cintura, cruzo os braços, tudo isso vai da roupa. Então quando coloco essa roupa já me sinto bem melhor para dançar. Dá um diferencial, me 
sinto como se estivesse naquela época dançando: eu numa roda com a Rock Steady $\mathrm{Crew}^{18}$. (Informação verbal) ${ }^{19}$

Para os dançarinos da Maré, o break dance teve uma ação transformadora em suas vidas, promovendo profundas alterações no seu quotidiano. Faziam questão de reiterar a importância do conhecimento no hip-hop ${ }^{20}$, incentivador de um conjunto de normas e valores associados não só à ética da dança ${ }^{21}$, mas também à disciplina que se exige de um dançarino de alta competição. Embora a maior parte do conhecimento pesquisado por esses jovens fosse restrito às questões relativas à cultura hip-hop, o envolvimento com o estilo promoveu o acesso a um conjunto de capitais culturais e simbólicos mais abrangentes. A adesão à dança expandiu o campo de possibilidades individuais desses jovens ao permitir que conhecessem pessoas de variados quadrantes culturais e passassem a transitar entre diferentes grupos sociais, contribuindo para que alguns deles desempenhassem papéis de mediadores culturais. Por outro lado, o break dance fomentava a união e um sentimento de pertença (ao grupo e ao bairro), uma via singular de entrada na sociedade, ao proporcionar-lhes significados partilhados e uma sociabilidade específica que os distinguia das massas.

\footnotetext{
${ }^{18}$ A Rock Steady Crew foi formada no fim da década de 1970 por alguns b-boys do Bronx, Nova York. É uma das mais famosas crews de break dance, responsável pela popularização do estilo no mundo.

${ }^{19}$ Entrevista concedida ao autor por Igor, dançarino de break dance, no dia 03 de novembro de 2010, Rio de Janeiro/Brasil.

${ }^{20} \mathrm{O}$ "conhecimento" é considerado o 5o elemento do hip-hop (formado pelo Mc, Djing, graffiti $e$ break dance), acrescentado por Africa Bambataa (um dos fundadores do movimento).

${ }^{21}$ Havia um código de conduta entre eles que condenava a cópia de movimentos ou uma dança demasiado centrada nos power moves. Os "fundamentos", termo utilizado para se referir à base dos movimentos do break dance (top rock, footwork e freeze), deviam ser priorizados, tal como a originalidade na sua execução.
} 
Otávio Raposo

Imagem 2: Treino de break dance na Tecno

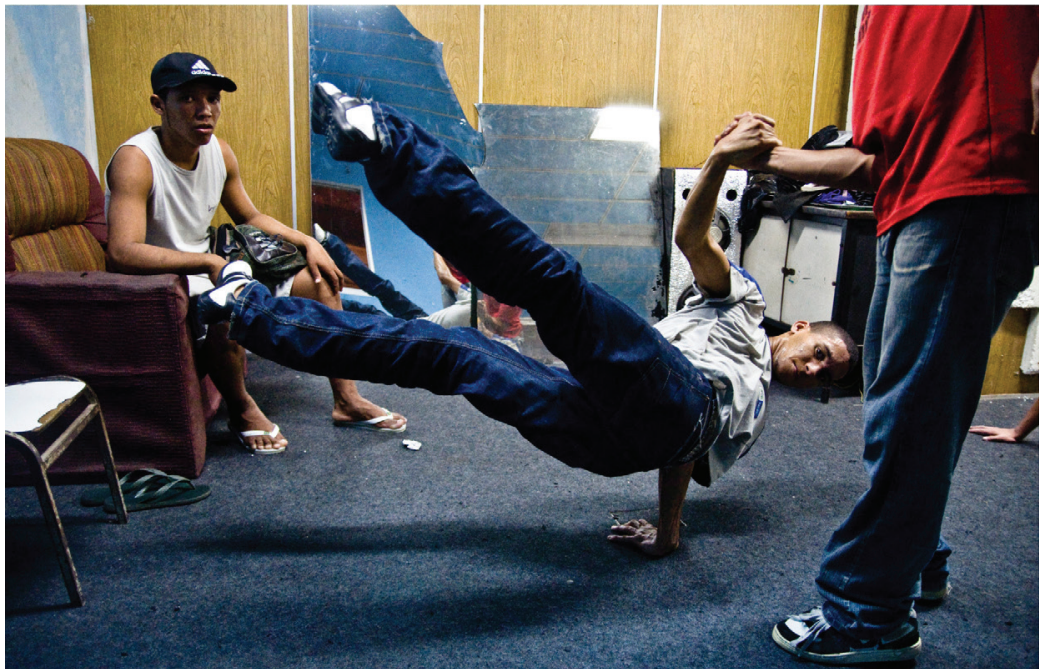

(Fotografia cortesia de William Oliveira, Outubro de 2009)

A experiência com a dança não estava isolada de outras esferas das suas vidas pessoais. Pelo contrário, havia uma forte comunicabilidade, pois estarem três vezes por semana a treinar após um intenso dia de trabalho e/ou de estudo gerava uma autodisciplina que eles diziam utilizar noutros desafios das suas vidas. Participar em campeonatos ou eventos de break dance forçava-os a juntar dinheiro para inscrições e viagens, o que tornava imprescindível estar a trabalhar. Dar palestras sobre hip-hop para um público de classe média forçava-os a falar português correto sem palavrões ou gírias, o que indiretamente valorizava a frequência escolar.

Quando eu comecei a dançar break dance eu comecei a pegar algumas coisas que aconteciam no breaking e levar para a minha vida; conforme foi passando o tempo virou um estilo de vida [...] Numa apresentação você não vai poder ficar zoando e xingando. Você tem que ter uma certa postura para aquele ambiente, ter um certo comportamento. 
Então eu comecei a adquirir isso na minha vida, tipo: "se eu tenho um certo comportamento quando vou dançar por que eu não posso ter aqui também? Se eu falo desse jeito ali, por que eu não posso falar aqui também?" Então teve essas trocas que eu puxei do breaking e levei para a minha vida, e teve coisas da minha vida que eu levei para o breaking, como o meu caráter. (Informação verbal) ${ }^{22}$

A prática do break dance não pode ser compreendida sem associá-la à busca de um sentido para a vida e à realização pessoal. Os jovens da Maré querem ser reconhecidos e respeitados como bons dançarinos, recusando a imagem de desempregados, marginais ou favelados. A adesão a uma crew de dançarinos respeitada no circuito de break dance carioca deve ser entendida como um instrumento nesse sentido, sendo um símbolo de afirmação que proporciona prestígio e um espaço de criatividade cultural.

\section{A rua segundo rappers e $b$-boys}

É a experiência que os jovens partilham nas ruas que compõe o "corpo ideológico da cultura hip-hop", tratando-se de um fenômeno urbano, juvenil e de rua (FRADIQUE, 2003, p.42). 0 ato de representar o hip-hop, seja através da dança, da música, do graffiti, seja enquanto consumidor, é a forma privilegiada de dar suporte ao movimento e requer uma participação afirmativa no seu seio. Serve para marcar uma posição e passar uma mensagem, indo contra os posicionamentos e as atitudes submissas incentivadas pelas instituições de ensino, políticas e de segurança pública.

Entre os rappers da Arrentela, representar a rua ou o bairro em que moram era uma atitude muito valorizada, pois significava colocar na cena pública não apenas a si, mas todos aqueles que

${ }^{22}$ Entrevista realizada pelo autor com Igor, dançarino de break dance, no dia 26 de agosto, 2010, Rio de Janeiro/Brasil. 
pertenciam à crew. Essa explícita ligação à rua foi explicada pelo rapper Chullage.

A rua é o teu apoio, é o teu chão, a tua fonte de inspiração, é tudo, meu, onde estão os teus tropas, tás a ver. Tu representas o teu people, o teu people é representado por ti e teu people o apoia, você tem que ter sempre a tua street nas tuas costas. É esse amor que a street dá que é estruturante para continuares. Acho mesmo que o rapper quando vem de um bairro tem que procurar esta ligação, é seres responsável por representar para o bem a tua zona, e representar a luta dos teus tropas. (Informação verbal) ${ }^{23}$

Tema principal das letras de rap do Red Eyes Gang, a rua é um espaço dotado de sentido ao evocar uma série de memórias coletivas associadas às suas experiências de vida. A veracidade e a pertinência das rimas eram sempre postas à prova, e precisavam obedecer a um conjunto de códigos morais - ser real e verdadeiro naquilo que cantam, por exemplo - sendo considerados fake ou sucker aqueles que contrariavam tais princípios. 0 conteúdo das letras devia ter como fim a denúncia do que estava mal na sociedade e servir de resistência a um sistema que oferecia poucos incentivos para romper com a pobreza e opressão.

Nos finais de semana, especialmente no verão, não era difícil encontrar nas ruas da Arrentela aglomerações com mais de trinta jovens conversando ou jogando bola. Para um olhar distante, os jovens quando reunidos não estariam a fazer nada, apenas a ver o tempo passar. No entanto, para Pais, o "não fazer nada é uma atividade de intensa produção de sociabilidade" (PAIS, 2003, p. 131), ao ser um tempo privilegiado para pôr a conversa em dia e criar sentimentos de pertença comum. Era o que via a acontecer entre os jovens da Arrentela. Enquanto conversavam, atualizavam-se sobre o panorama musical, trocavam informações

${ }^{23}$ Entrevista realizada pelo autor com o rapper Chullage, no dia 19 junho de 2006, Seixal/Portugal. 
relativas ao mercado de trabalho, combinavam saídas noturnas e cumprimentavam os amigos ou conhecidos que passavam por eles (a pé ou de carro) numa espécie de celebração ao vínculo afetivo que os unia. Podemos dizer que, em alguns locais da Arrentela, os jovens criavam pontos de referência e de identificação local que se aproximavam da definição de "pedaço" proposta por Magnani (2007), territórios onde são tecidos códigos e cumplicidades produtoras de sociabilidades particulares que só os mais chegados dominam. Assim, era o caso do muro onde costumavam estar. Embora fosse um local público, continha características privadas, em que assuntos de âmbito particular (para os jovens) e proibidos (para os de fora) eram tratados, onde pessoas estranhas ao grupo eram vistas com desconfiança. Aliás, foi para dar substância a essa forma de identificação grupal que os jovens da Arrentela criaram o Red Eyes Gang.

Imagem 3: Rappers da crew Red Eyes Gang a cantar

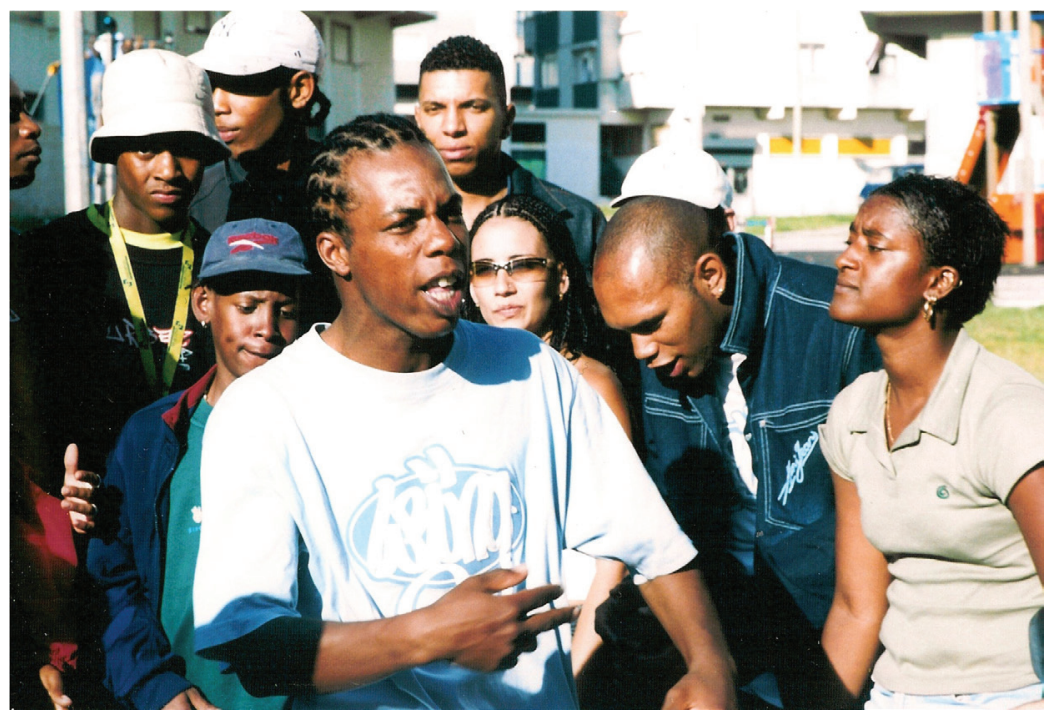

(Fotografia de Otávio Raposo, Julho de 2004) 
Apesar da importância do bairro para os jovens da Arrentela, não estavam isolados no seu interior e estabeleciam uma rede de trajetos nos espaços lúdicos de Lisboa. Eram os rappers da crew aqueles que mais circulavam pela cidade, pois a adesão ao estilo incitava-os a darem concertos noutros bairros e a estabelecer parcerias com músicos de outras regiões, ampliando as suas redes de amizade. Configuravam novos "circuitos" ${ }^{24}$ de sociabilidade e de consumo que valorizavam as áreas estigmatizadas da cidade, cuja frequência aos bairros mais pobres contribuía para uma inovadora concessão do urbano ao subverter os fluxos convencionais de centro-periferia fomentados pelo poder instituído.

Diferente dos rappers da Arrentela, o convívio dos b-boys e b-girls da Maré concentrava-se fora do espaço público e tinha como principal objetivo o aprimoramento da dança. Contudo, o ambiente festivo e as conversas em tom jocoso tornavam a Tecno muito mais que um mero local de treino. Cenário de densas sociabilidades, era o lugar onde podiam conversar à vontade sobre o que quisessem e divertir-se sem se sentirem vigiados por pessoas de fora. Uma aprendizagem não formal era posta em cena, cujos limites extravasavam as performances corporais. Discutiam problemas e alegrias do quotidiano, gostos musicais, estéticos e éticos. Reforçavam a união e a amizade entre os membros do grupo ao elaborar um "nós": nós, os do break dance. E buscavam a singularidade ao diferenciarem-se de outras culturas juvenis presentes na Maré, ao mesmo tempo em que rejeitavam uma visão uniforme dos jovens da favela.

O salão onde treinavam oferecia certa proteção da violência do tráfico e da polícia, assim como das influências decorrentes da

${ }^{24}$ De acordo com Magnani (2007), podemos entender por "circuitos" toda a rede de espaços, equipamentos e estabelecimentos que determinados agrupamentos juvenis utilizam no estabelecimento dos seus encontros, conflitos e relações de troca. Essa noção quer chamar a atenção para a vasta gama de sociabilidades desenvolvida pelos jovens no espaço urbano, o que poderá proporcionar uma visão mais contextualizada das suas práticas sociais e dos espaços com os quais interagem. 
proximidade com um pujante mercado de venda de drogas. A presença de jovens fortemente armados e o risco de haver um tiroteio a qualquer momento tornavam as ruas da Maré pouco atraentes para a maioria dos dançarinos. Tal apreciação era agravada pela forte densidade populacional do bairro e escassez de espaços públicos que proporcionassem uma conversa tranquila e intimista. Por isso, a Tecno servia de refúgio contra os riscos da rua, um espaço protegido que desempenhava o "papel de escudo" contra as violências rotineiras que assolavam o bairro. ${ }^{25}$ Isso não quer dizer que houvesse um fechamento dos b-boys em relação à rua ou aos acontecimentos do bairro. Pelo contrário, era nos treinos de break dance que se ensaiavam estratégias inovadoras de aceder ao espaço público ${ }^{26}$, criavam-se representações alternativas sobre o bairro e desenvolviam-se novos trajetos pela cidade. A vontade de participar de eventos e campeonatos de break dance tornava os treinos da Tecno a "rampa de lançamento" para saírem do bairro e realizarem as mais variadas incursões pela urbe. A percepção da importância do hip-hop no incentivo à sua circulação para outros territórios da cidade era unânime entre eles, que admitiam o fato de pouco saírem da Maré antes de praticarem a dança. Tornou-se comum a participação em eventos e campeonatos em bairros nobres do Rio de Janeiro ou noutras favelas, como Rocinha e Vidigal, ou irem a encontros de break dance noutras cidades brasileiras.

${ }^{25}$ Encontrei várias semelhanças entre a Tecno e a academia de boxe pesquisada por Loic Wacquant (2002) num bairro do gueto negro norte-americano. Ambas eram "ilhas de estabilidade e virtude", ao imprimirem um conjunto de valores e referências aos jovens que se opunham às influências exercidas pela economia do tráfico de drogas.

${ }^{26}$ Os meses em que treinaram numa das praças da Nova Holanda foram exemplares das inovadoras estratégias de reapropriar a rua e as áreas comuns do bairro. 
Imagem 4: "Roda de break dance na Tecno"

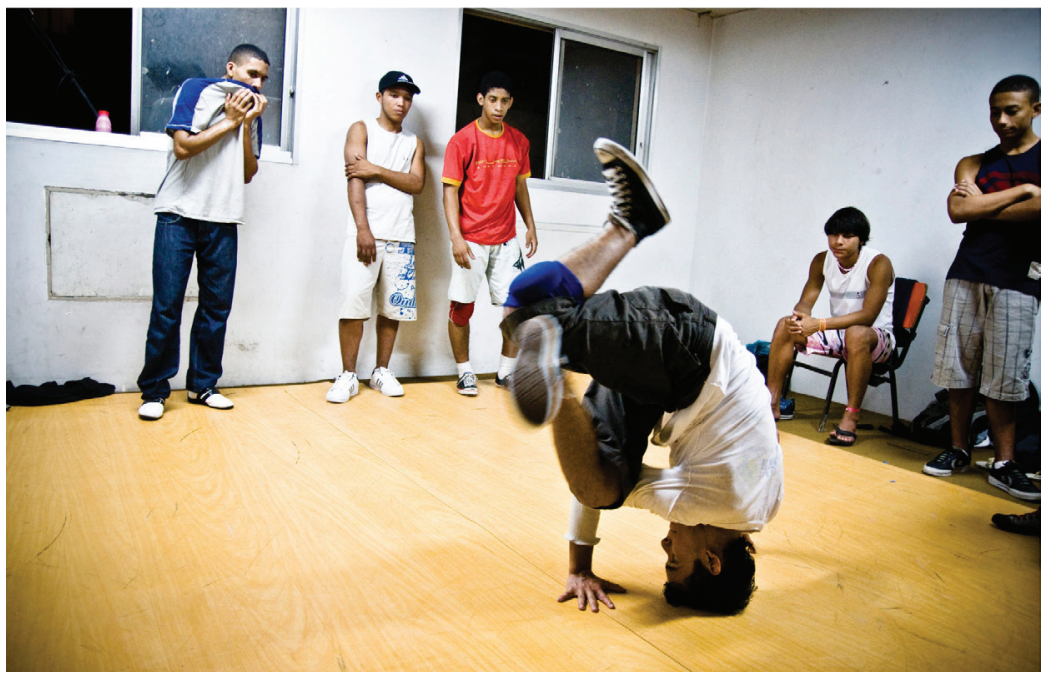

(Fotografia cortesia de Willian Nascimento, Outubro de 2009)

A cultura hip-hop como disparador de ações e de encontros fomenta o fluxo dos jovens pelo espaço urbano, pondo-os em contato não só com jovens de outros bairros e classes sociais, mas também com os múltiplos repertórios, saberes e estilos de vida da metrópole. Circular pela cidade, participar de campeonatos de break dance ou concertos de rap, dentro ou fora da sua área de residência, tornou-se configurador de quem são. Deixaram de ser sujeitos passivos para se transformarem em criadores ativos, exercendo uma cidadania insurgente que propõe novos usos da cidade ao desenvolver ações mobilizadoras que disputam o significado de ser pobre, negro e morador de bairros estigmatizados. Por isso, o break dance, para os jovens da Maré, e o rap, para o Red Eyes Gang, atuariam como uma cultura de evasão, estimulando-os a refletir sobre o seu lugar no mundo através de projetos artísticos e culturais que contribuem para dar sentido à sua existência. 


\section{"Sistema tenta, mas não nos comanda". D ois olhares sobre a segregação}

A angústia do desemprego entre os jovens da Arrentela obrigava-os a aceitar trabalhos precários na construção civil (homens) ou nas limpezas (mulheres). A longa crise econômica em Portugal agravou as condições de vida dessa juventude, já situada entre os setores mais vulneráveis da população. ${ }^{27}$ Diferente da maior parte dos seus pais, que efetuou um percurso migratório, esses jovens foram criados numa sociedade de consumo cuja influência da globalização e dos novos meios de comunicação fez crescer as suas expectativas. Eles partilhavam padrões e estilos de vida próximos da classe média, mas as suas oportunidades mantiveram-se estagnadas (ou regrediram) quando comparadas às de seus pais, agudizando o sentimento de privação ${ }^{28}$. As restritas oportunidades laborais dificultavam a possibilidade de consumo, entendido como um dos instrumentos privilegiados de acesso à cidadania.

A pior coisa que tem é um gajo estar pregado na street e não ter dinheiro nenhum no bolso. Se um gajo tem dez ou quinze euros já nos sentimos melhor, mas não ter nada não nos faz sentir homens, não podemos comer um bolo, tomar uma cerveja com os rapazes ou jogar um snooker. (Informação verbal) ${ }^{29}$

\footnotetext{
${ }^{27}$ Cerca de $42 \%$ dos jovens da crew estavam desempregados em 2006, um número bem superior à média portuguesa. Entre os que trabalhavam quase todos desempenhavam atividades mal remuneradas, precárias e desvalorizadas socialmente (obras, McDonald's, restauração ou limpezas); e apenas 8,3\% tinham contrato de trabalho. Cf. RAPOSO, 2007. ${ }^{28}$ Com o agravamento da crise econômica nos últimos anos, a emigração para outros países europeus foi a solução encontrada por muitos jovens Red Eyes Gang para lidar com os altos índices de desemprego. De fato, as ruas da Arrentela (e de outros bairros da periferia de Lisboa) já não reúnem tantos jovens como no período em que realizei a pesquisa de mestrado, o que revela a intensificação do fenômeno da emigração juvenil na sociedade portuguesa. Vale ressaltar que a partir de 2011, ano em que teve início a intervenção da Troika (Comissão Europeia, Banco Central Europeu e FMI) em Portugal, as taxas de emigração cresceram substancialmente, especialmente da sua população juvenil. Só em 2013 e 2014, a taxa de emigração foi superior a 100 mil pessoas por ano (PIRES, 2015). ${ }^{29}$ Entrevista realizada pelo autor com o rapper Gringo, no dia 05 julho de 2006, Seixal/ Portugal.
} 
A pouca identificação com a escola, o hiato que os separava das organizações políticas / sociais e o ódio pela polícia, decorrente da brutalidade policial, faziam com que esses jovens construíssem as suas referências positivas por fora das instituições formais, aproveitando o espaço urbano à sua volta e os laços informais que estabeleciam entre si. Pertencerem às classes desfavorecidas sem vislumbrarem perspectivas de melhorar as suas condições de vida levava a que o estilo rap para esses jovens se estruturasse em torno de uma cultura de rua que atuava como um grito de revolta contra a sociedade dominante. Para Philippe Bourgois, a cultura de rua entre os jovens descendentes de porto-riquenhos de El Barrio, Nova Iorque, constituía:

A complex and conflictual web of beliefs, symbols, modes of interaction, values and ideologies that have emerged in opposition to exclusion from mainstream society. Street culture offers an alternative forum for autonomous personal dignity $^{30}$. (BOURGOIS, 2003, p. 38)

A cultura de rua entre os jovens Red Eyes Gang também incitava-os a práticas rebeldes que, por vezes, ultrapassava as fronteiras da legalidade, e dotava-os de um conjunto de imaginários que lhes dava a ilusão de construírem uma ordem social e simbólica em que eram eles a ditar as regras do jogo. É o que podemos constatar no extrato da música Polítika de Rua do rapper Kosmikilla:

A situação política é que manda/ Babilônia tenta mas não nos comanda/ A situação política é que manda/ Sistema tenta mas não nos comanda, mas não nos comanda/ Kosmikilla ninguém comanda/ Arrentela ninguém comanda/ Red Eyes Gang ninguém comanda/ O hip-hop ninguém comanda! (KOSMIKILLA, 2003)

\footnotetext{
${ }^{30}$ Segundo a tradução livre do autor: "Uma rede complexa e conflitiva de crenças, símbolos, formas de interação, valores e ideologias que tomaram forma como uma resposta à exclusão da sociedade convencional. A cultura de rua apresenta-se como um fórum alternativo em que a dignidade pessoal pode manifestar-se de maneira autônoma".
} 
Entre os b-boys da Maré, o antagonismo com a sociedade dominante pareceu-me ser muito menor ao demonstrado pelos rappers da Arrentela. Ao contrário do Red Eyes Gang, os b-boys da Maré mobilizavam estratégias de aproximação às instituições (organização não governamentais, escolas, etc.) através do hip-hop com o objetivo de seduzir e serem aceitos pelos setores mais privilegiados. Seguiam um estilo de vida imbuído de disciplina e ensaios regulares que, aliado às novas redes sociais sustentadas a partir de "projetos de mediação" (VELHO, 2001), estimulava a incorporação de projetos de ascensão social parecidos com os das classes médias. Exemplo disso era a aposta de muitos deles na educação; alguns ambicionavam entrar na universidade ou frequentavam cursos profissionalizantes de fotografia, web-design e informática. Embora o poder aquisitivo das famílias da Maré fosse bem mais baixo quando comparado ao dos moradores da Arrentela, o crescimento econômico do Brasil, no período em que fiz a pesquisa, diminuiu o desemprego entre os jovens do bairro e aumentou a qualidade de vida da população ${ }^{31}$.

Ao enfrentarem níveis de violência radicalmente superiores aos da Arrentela, os moradores da Maré são obrigados a conviver com bandos armados e comércio de drogas ao lado das suas casas, o que afeta gravemente as suas rotinas. Vivem uma "cultura de terror" e de submissão que os afasta do espaço público (BOURGOIS, 2010, p.62), assim como dificulta o pleno acesso à justiça em virtude do estigma que os considera cúmplices dos traficantes. A influência desses grupos armados não se limita ao domínio territorial, mas também se impõe em formas lúdicas de sociabilidade. Os bailes funk, espaço de diversão por excelência dos jovens da Maré, são organizados pelo tráfico de drogas, responsável pela contratação das equipas de som, dos Djs e por garantir a "segurança" no local. Essa influência reflete-se nas letras de funk tocadas nesses

\footnotetext{
${ }^{31}$ Entre 2000 e 2010 houve uma significativa queda da pobreza motivada pelo forte aumento da renda - cresceu em média $67,93 \%$ entre os $50 \%$ mais pobres -, segundo a pesquisa coordenada por Marcelo Neri (2011). Conclui este pesquisador, da Fundação Getúlio Vargas, que a pobreza no Brasil caiu 50,54\% entre 2002 e 2010.
} 
bailes, cujos temas abordados são quase exclusivamente alusivos ao sexo e destinados a glorificar a quadrilha que domina o tráfico na região. Apelidadas de "proibidão ${ }^{32}$ ", essas músicas não passam nas rádios (a não ser em versões suavizadas), tampouco são comercializadas legalmente. Mas na Maré a omnipresença desse tipo de funk no espaço público é tão forte que abafa outros gêneros musicais como o samba, rap, forró ou pagode. 0 forte teor erótico de algumas das suas letras, aliadas a outras que fazem apologia ao tráfico de drogas, gera críticas tanto de moradores como de pessoas de fora (jovens ou não). A maioria dos b-boys da Maré acusava o funk de produzir mensagens que pouco contribuíam para a reflexão sobre a sociedade em que vive e de vincular simbolicamente seus fãs aos grupos criminosos que comandam a sua área de residência. Antítese de tudo aquilo que a cultura hip-hop simbolizaria, o funk "proibidão" encarnava um conjunto de imaginários e práticas que os b-boys queriam afastados das suas vidas. Por isso, a vivência do break dance entre os dançarinos do bairro fê-los aproximar de um conjunto de valores e condutas associados à cultura hip-hop antagônicas às influências destrutivas da economia do tráfico. A promoção de narrativas simbólicas e culturais que não se reveem na estrutura de oportunidades oferecidas pelo tráfico de drogas tornava o break dance uma "escola de moralidade", cujo impacto na estrutura de valores e emoções dos adeptos propunha com algum sucesso possibilidades de status e ascensão social alternativos ${ }^{33}$ (WACQUANT, 2002, p.32).

32 O funk carioca, uma das maiores manifestações culturais de massa no Brasil, é complexo e diverso, não podendo ser resumido ao "proibidão", uma das versões deste estilo musical. Há um grande número de MCs (Leonardo, Júnior, Dolores, Galo, entre outros) que se recusa a fazer canções com conotações claramente sexuais ou de glorificação do tráfico de drogas, priorizando composições que abordam o amor, as injustiças sociais, a alegria e as vivências do quotidiano.

${ }^{33}$ Embora admita que a ligação dos jovens ao hip-hop possa servir de "abrigo virtual" num meio marcado por situações predatórias e adversas (AGIER, 200, p.8), esta "cultura" não pode ser entendida como solução para os problemas de uma violência juvenil que é expressão de dilemas estruturais mais amplos da sociedade brasileira, tais como a extrema desigualdade social, a inconsistência das políticas públicas do Estado, a precariedade laboral e a criminalização da pobreza e do consumo de drogas. 
Na Arrentela, a violência era excecional e não interferia no quotidiano dos moradores. 0 tráfico de drogas era realizado disfarçadamente, sem qualquer organização, e os seus efeitos colaterais não tinham paralelo com a Maré: não se viam armas, as mortes eram raras e os confrontos com a polícia de outra intensidade. Todavia, a violência incorporava muito mais aspectos da identidade masculina do Red Eyes Gang do que dos b-boys da Maré. Se a principal demarcação da diferença para estes girava em torno da divisão entre bandido e trabalhador - era frequente o uso de categorias "nós" e "eles" para reafirmar esta distinção -, na Arrentela tal separação era bem mais ambígua. 0 roubo e o tráfico de drogas, embora praticados por uma pequena minoria, eram alternativas de sobrevivência aceitáveis ou mesmo justas dado o desemprego gritante, não sendo atividades tão perigosas como na Maré $^{34}$. Era na articulação entre o estilo de vida rap, o território e a sua origem social enquanto pobres e negros que o Red Eyes Gang demarcava as fronteiras com outros grupos sociais.

0 forte estigma vivido pelos jovens da Arrentela e o fato de muitos não serem plenamente aceitos como portugueses ${ }^{35}$ acirravam ainda mais a sua insubordinação. Ao serem rotulados pela mídia e pelas instituições políticas de "imigrantes de segunda geração", produz-se uma ideologia de incompatibilidade entre os jovens negros e a cultura portuguesa baseada na racialização

\footnotetext{
${ }^{34}$ O Brasil é o país com maior número de homicídios no mundo em termos absolutos (WAISELFISZ, 2011), grande parte vítimas do envolvimento com o tráfico de drogas. Entre os anos 2004-2007, mais de 190 mil pessoas foram assassinadas, a maioria jovem, pobre e negra. Na Maré os confrontos armados entre quadrilhas rivais ou com a polícia não eram excecionais, tendo existido mais de 40 assassinatos entre os meses de maio e novembro de 2009, segundo informações de moradores e organizações não governamentais do bairro.

${ }^{35}$ Parte significativa dos jovens filhos de imigrantes africanos não tiveram direito à nacionalidade portuguesa mesmo quando nascidos em Portugal, em consequência das limitações impostas pelo critério jus sanguinis. Ou seja, era preciso ser filho de português para a obtenção da nacionalidade portuguesa. A partir de 2006 houve uma flexibilização da lei, garantindo aos filhos de imigrantes nascidos em Portugal a nacionalidade portuguesa desde que um de seus pais estivesse regularizado há, pelo menos, cinco anos. Cf. RAPOSO, 2007 e VERBO JURÍDICO, 2006.
} 
da diferença cultural. A consequência desse processo é a impermeabilização da fronteira étnica da população portuguesa e a desidentificação dos descendentes de imigrantes com Portugal. Essa dinâmica era bastante visível entre os rappers negros da crew - a maioria afirmava não se sentir português -, cujas letras denunciavam o racismo de que eram alvo, ao mesmo tempo que valorizavam as suas referências negras e africanas. É o caso da letra de rap Pretugal, título que por si só incorpora uma sátira ao racismo ao fundir o termo "preto" com Portugal:

Koração lá e korpo ká em pretugal/ Mentalmente enkkkarcerados ká em pretugal/ Sem pão, mas kom veneno e armas p'ra morrermos em pretugal/ Segregados p'ra ñ sermos ninguém em Portugal. (CHULLAGE, 2004)

Imagem 5: Jovens da Arrentela a participar no vídeo-clipe do rapper Kosmikilla

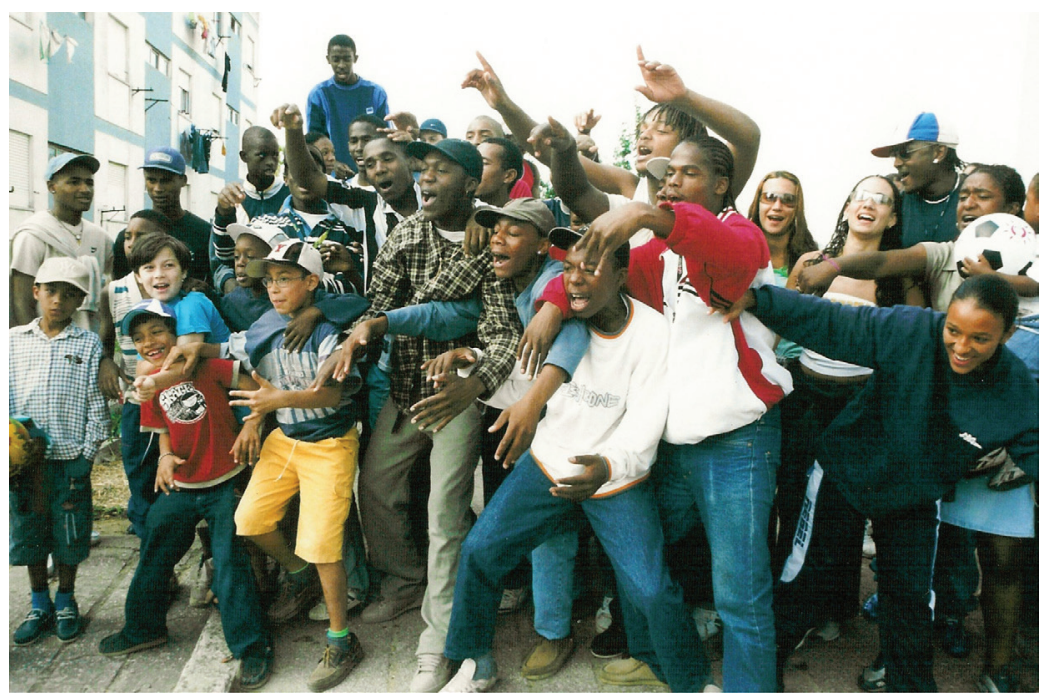

A forte segregação vivida pelos membros do Red Eyes Gang levava a que as questões étnicas e de classe fossem sentidas de maneira unificada. No entanto, os persistentes fenômenos de racismo, inclusive praticados por vizinhos da mesma condição social, 
tornavam a cor da pele a lente para interpretar a marginalização a que eram relegados. Os jovens da Maré não utilizavam o break dance como um modo de afirmar a negritude, tampouco faziam do estilo um instrumento de luta contra o racismo, problema raramente debatido entre eles. Como explica Renato, um b-boy da Maré que também faz graffiti:

Cara, a gente só procura viver e nem lembra muito dessas questões raciais. Porque para a gente a cultura hip-hop está acima de tudo, independente da cor. A gente não impõe muito esses assuntos não. Sei lá, não é nem porque a gente não quer. Mas claro que se um colega nosso sofrer racismo a gente vai ficar sabendo e não vai gostar. Mas esses assuntos a gente não conversa não, porque a gente não vê necessidade. A gente não quer pensar nisso, que isso é um problema, sacou. (Informação verbal) ${ }^{36}$

Não negavam a existência do racismo, principalmente nas áreas ricas da cidade, mas davam pouca importância a tal fenômeno. Inúmeras vezes ouvi os b-boys da Maré dizerem "aqui é tudo junto e misturado", e nas entrevistas realizadas havia uma clara exaltação de um Brasil mestiço ${ }^{37}$. Diferente de Portugal, os não-brancos no Brasil são a maioria da população, e alguns símbolos da negritude foram incorporados na identidade nacional. Segundo Livio Sansone (2007), os negros brasileiros não se sentem pertencentes a uma minoria étnica, e o apego à nação é constantemente manifestado em múltiplos rituais, expressando um orgulho negro sem a etnicidade. As tensões grupais na Maré raramente adquiriam contornos étnicos, pois brancos, negros e mestiços sentiam-se marginalizados pelo Estado e partilhavam

${ }^{36}$ Entrevista concedida para o autor pelo dançarino de break dance e grafiteiro, Renato, no dia 18 de setembro de 2010, Rio de Janeiro/Brasil.

${ }^{37} \mathrm{~A}$ ideia de democracia racial pautou as reflexões sobre as relações raciais no Brasil desde a década de 1930, quando Gilberto Freyre transformou a mestiçagem no elemento definidor da identidade nacional. Mais do que um mito, esta ideia é reproduzida na vida quotidiana, sendo aceita pela ampla maioria da população, principalmente nas classes baixas. Cf. SANSONE, 2007. 
problemas comuns, não sendo um mito as solidariedades inter-raciais vividas no bairro. Mais do que dividirem o mundo em torno de uma polaridade branca e outra negra, os jovens do bre$a k$ dance da Maré organizavam as suas vivências segundo um continuum de cor, cujas fronteiras eram marcadamente fluídas, variando conforme o contexto. Ser pobre e morador de favela configuravam as chaves-explicativas para compreenderem as injustiças de que eram alvo, tal como o seu baixo estatuto. Não era por acaso que, nos eventos de dança, os b-boys da Maré faziam questão de assumir em público o bairro onde viviam, uma forma de pôr em causa os estigmas que os caracterizavam como criminosos em potencial. Ao vencerem campeonatos de dança projetavam uma visibilidade que os representava como potência e não mais numa situação de carência, saltando as barreiras simbólicas que os queriam circunscritos ao rótulo de favelado. Esse processo de rotulação foi denunciado por Rômulo, um dos b-boys da Maré:

É como se dessem as informações de que nós fôssemos "pré-fabricados" como marginais. Acho que isso é algo que tem de mudar, tem de mudar. Não é pelo fato de nós morarmos numa comunidade que a gente vai seguir o nome de "favelado" à risca, entendeu. Até porque "favelado" [...] Eu posso até dizer que moro numa favela, moro numa comunidade, agora nós não somos ignorantes. Acho que muito pelo contrário [...] Dependendo do lugar, quando o cara fala que veio da zona sul [área nobre da cidade], a galera já fica mais tranquila. Mas quando você vê alguém bom que sai de dentro de uma comunidade, a pessoa fica meio que sem chão porque ela quer saber o que é que aconteceu para que o cara ficasse bom daquele jeito: "Porra! Como é que ele ficou assim dentro de uma favela? Aí tem coisa [...] Já fica curioso, mas com o pé atrás. (Informação verbal) ${ }^{38}$.

${ }^{38}$ Entrevista concedida para o autor pelo dançarino de break dance e grafiteiro, Rômulo, no dia 05 de novembro de 2009, Rio de Janeiro/Brasil. 


\section{Considerações Finais}

Para os dançarinos da Maré e os rappers da Arrentela o hip-hop era um meio de obter reconhecimento e reivindicarem a participação no mundo contemporâneo, ao verem a si próprios como integrantes de uma prestigiada cultura global. Para os primeiros, o desejo de ser alguém era realizado parcialmente através da break dance, farol de virtude que os resguardava da violência exacerbada do bairro. 0 estilo era uma mais-valia para romper com a segregação e a engessada mobilidade social brasileira, sem, no entanto, exercer uma postura antagônica à sociedade dominante. Entre o Red Eyes Gang, a busca por respeito e dignidade entrava em constante choque com os mecanismos tradicionais de afirmação e ascensão social, o que era agudizado pelo sentimento de rejeição da sociedade portuguesa. Imbuído de referências culturais africanas, o estilo rap questionava as relações de hegemonia e subalternidade presentes no seu dia a dia, ressituando-as num contexto de luta por um lugar na sociedade. Num contexto em que a pobreza, a violência e o déficit de oportunidades comprometiam as expectativas e os percursos dos jovens na Arrentela e na Maré, distintas estratégias eram delineadas através do hip-hop na tentativa de superarem as incertezas da vida e desfrutarem das alegrias da juventude.

\section{Bibliografia}

AGIER, Michel. Distúrbios Identitários em Tempos de Globalização. Mana. Estudos de Antropologia Social, Rio de Janeiro, v.7, n.2, p.7-33, 2001.

BOURDIEU, Pierre. O poder simbólico. Rio de Janeiro: Bertrand, 2007.

BOURGOIS, Philippe. In search of Respect. Selling crack in El Barrio. NewYork: Cambridge University Press, 2003.

CHULLAGE. Rapensar. Passado, presente e futuro. [Registo Sonoro]. Seixal: Editora Lisofonia. 1 álbum (CD), 2004. 
FEIXA, Carles. De Jóvenes, Bandas y Tribus. Barcelona: Editora Ariel, 1999.

FRADIQUE, Teresa. Fixar o Movimento - Representações da música rap em Portugal. Lisboa: Dom Quixote, 2003

GIDDENS, Anthony. Modernidad e identidad del yo: el yo y la sociedad en la época contemporánea. Barcelona: Península, 1995.

KOSMIKILLA. Polítika de Rua. [Registo Sonoro]. Seixal: Editora Kombate. 1 álbum (CD), 2003.

MAGNANI, José G. Introdução. Circuito de Jovens. In: Magani, J.G. \& Souza, B.M. (Org.). Jovens na Metrópole: etnografias de circuitos de lazer, encontro e sociabilidade. São Paulo: Terceiro Nome, 2007. p. 15-22.

NERI, Marcelo. Desigualdade de Renda na Década. Rio de Janeiro: Fundação Getúlio Vargas, 2011. Disponível em: www.cps.fgv.br/cps/bd/DD/DD_Neri_Fgv TextoFim3.pdf [Acesso em: 12 jan. 2012].

PAIS, José M. "Jovens, bandas musicais e revivalismos tribais". In: PAIS, José M. e BLASS, Leila M. (Org.). Tribos Urbanas. Produção artística e identidades. Lisboa: Imprensa de Ciências Sociais, 2005, pp.23-55.

PAIS, José M. Culturas Juvenis. Lisboa: Casa da moeda, 2003.

PAIS, José M. A geração yô-yô. In: Proceedings of the third Congresso Luso-Afro-Brasileiro de Ciências Sociais. Dinâmicas multiculturais. Novas faces, outros lugares. Lisboa: Instituto de Ciências Sociais da Universidade de Lisboa, 1994, p. 111-125.

PIRES, Rui Pena. "Mais de 100 mil saídas pelo segundo ano consecutivo". Observatório da Emigração. Disponível em: <http://www.observatorioemigracao.pt/np4/4581.html>. Acesso em: 16 de out. 2015.

RAPOSO, Otávio. "Redes Periféricas Transatlánticas II: Brasil y Portugal en foco". In: MARTINS, Rosana (Org.). Hip-hop, Cultura y Participación. La visibilidad da la juventud de las periferias urbanas. Barcelona: Editorial UOC, 2015, p.125-151.

RAPOSO, Otávio. "A insistência no mito favela". In: CACHADO, Rita A. e BAÍA, João (Org.), Políticas de habitação e construção informal. Lisboa: Editora Mundos Sociais, 2012.

RAPOSO, Otávio. Representa Red Eyes Gang: das redes de amizade ao hip hop. 2007, 191 f. Dissertação (Mestrado em Antropologia Urbana) - Instituto Universitário de Lisboa (ISCTE-IUL), Lisboa.

RAPOSO, Otávio (Direção). Nu Bai. 0 Rap Negro de Lisboa. 2006. Filme Documentário. Lisboa: Produção Independente. 
REDES - Redes de Desenvolvimento da Maré. Censo de Empreendimentos Maré, Rio de Janeiro: Redes da Maré \& Observatório de Favelas, 2014.

SANSONE, Livio. Negritude sem etnicidade: o local e o global nas relações raciais e na produção cultural negra do Brasil. Salvador: EDUFBA, 2007.

SILVA, Jailson S. e JORGE Luiz B. Favela: alegria e dor na cidade. Rio de Janeiro: SENAC Rio Editora, 2005.

VELHO, Gilberto. Biografia, trajetória e mediação. In: Velho, Gilberto \& Kuschnir, Karina (Orgs.) Mediação, Cultura e Política. Rio de Janeiro: Aeroplano, 2001 p. 13-28.

VELHO, Gilberto. Individualismo e Cultura: notas para uma antropologia da sociedade contemporânea. Rio de Janeiro: Jorge Zahar, 1987.

VERBO JURÍDICO. Lei da Nacionalidade. 2006. Disponível em: <www.verbojuridico.com/download/leinacionalidade.pdf > Acesso em: 14 fev. 2012.

VIANNA, Hermano. 0 mundo funk carioca. Rio de Janeiro: Jorge Zahar Editor, 1997.

WACQUANT, Loic. Corpo e Alma: notas etnográficas de um aprendiz de boxe. Rio de Janeiro: Relume Dumará, 2002.

WAISELFISZ, Julio J. Mapa da Violência 2012: os novos padrões da violência homicida no Brasil. São Paulo: Instituto Sangari, 2011.

Recebido em 26/12/2015

Aprovado em 30/12/2015 